\title{
Confucianism and the Education of Young People's Outlook on Life
}

\author{
Jian Kang* and Yajun Zhang \\ School of Marxism, Shaanxi University of Traditional Chinese Medicine, Xianyang, China
}

\begin{abstract}
The outlook on life is an important part of the "three outlooks" of young people and is of great importance to them. Many Confucian views such as life purpose, life ideals, human attitudes, life values, etc. should have a lot to teach today's youth about life.
\end{abstract}

\section{What is a view of life}

"Outlook on life" is the fundamental and basic view of life, A different outlook on life directly determines how one approaches one's life and one's relationships with others, and whether one can have a happy life is closely related to whether one has the right outlook on life. As President Xi Jinping said, "If the young generation has ideals and responsibilities, the country will have a future and the nation will have hope." [1]Youth is an important period in the formation of a view of life, and through reflection on life issue, a "consciousness of understanding" about life is formed, and these views and opinions are the foundation for later thinking and practice of life issue.

Unlike a static theorized worldview, the life view is an issue that bridges the dual domains of theory and practice, so that an individual's actions belong in meaning or outcome not only to himself but also to the social group as a whole, with varying degrees of social effect and impact. Research shows that there is a positive correlation between the "dedication", "collective", "dream" and "struggle" of young people in different degrees. There are different degrees of positive correlations between them, forming an organically linked whole. Increased identification with any one of the values promotes identification with the other three. [2] The ability to think appropriately and correctly about life issues is not only a matter of personal happiness, but also of the stability and health of society as a whole.

\section{Structure and characteristics of the Confucian view of life}

The Confucian view of life begins with the question of the essence of human, which in Confucianism can be summarized as "Ren, the human being". "Ren" as the essence of human nature, from a static point of view, is what Mencius called "the heart of sympathy", which is "compassion heart". This "compassionate heart", is innately rooted in human

\footnotetext{
* Corresponding author: 395172057@qq.com
} 
nature and is the primary and fundamental premise of all moral consciousness and emotions. From the "compassion heart" comes moral consciousness such as benevolence, righteousness, propriety and wisdom, thus building a human society characterized by a culture of ritual and music. In dynamic terms, "Ren" is what Confucius called "loving people", and "love" is the natural expression of "Ren" in empirical life, and is the inner requirement of "Ren". It is only through loving people that the inner heart of benevolence can be expressed.

Human beings are similar in nature, It is this similarity that makes "love" possible between human beings. The chinese characters "Ren" is form by "person" and "double" two characters, and it's realized and accomplished in the mutual relationship between people, "loving people" itself inherently contains the meaning of connecting with others. "Loving people" begins with serving relatives and ends with loving other people, so the beginning of "benevolence" also begins with "loving relatives is the greatest". In addition to this, it is necessary to be able to "proceed from the close to the distant": "to look at people from the perspective of the "category", to extrapolate from the individual to the "human being", from being close to oneself and one's closest relatives to loving all people. Love all the people of the world and be pro-people of the world." [3]"human nature is similar" guarantees the essential similarity of race, thus making it possible to promote "love" between people, starting with family love and continuing to push, thus the ethical bond of goodwill is formed. On the other hand, the proximity of blood relations in reality creates a differential pattern of affinity based on "human nature is similar", and thus a differentiated and diverse interpersonal relationship.

Confucianism also noted the problem of human alienation, attributing it to the loss of subjectivity in response to differences in historical circumstances, summarized as "falling of ceremony". "The loss of the culture of ritual and music has deprived people of their subjectivity and therefore of the ability to perceive the essence of benevolence. When the individual is no longer concerned with "learning for oneself," the "love people" loses its "I" as the subject, and without this core love, there is no inner motivation to push forward, and it cannot be carried out. The Confucian solution to this problem is to re-establish the selfsubject and to make the study of the "self" possible again. From the individual himself, the status of the subject is re-established by means of "cultivating oneself to respect"; from the subject, benevolent love is further promoted to realize "cultivating oneself to secure others"; when this love finally forms an ethical bond of goodwill, the ritual and music civilization of "cultivating oneself to secure the world" promised by Confucianism is realized again. When this love finally forms an ethical bond of goodwill, then the civilization of ritual and music, which Confucianism expects "to cultivate oneself in order to secure the world", is realized again.

\section{Exploration of Confucian culture in shaping the outlook of youth on life}

President Xi Jinping once said, "The rich philosophical ideas, humanistic spirit, edifying thoughts and moral concepts of China's excellent traditional culture can provide useful inspiration for understanding and transforming the world, for governing the country, and for moral construction." [4]Confucianism focuses on the spiritual uplifting and character building of the individual and fully explores the subjective initiative of the individual. This pursuit of transcending a finite life is of great value and significance to the shaping of the outlook of young people today. 


\subsection{The purpose of "to be a benevolent man" on life}

The purpose of life is the basic content of the concept of life. What kind of purpose of life determines what kind of value of life, what kind of human attitude to adopt and what kind of ideal of life to set. The Confucian purpose of life can be summarized as: to become a true nature human. As Mr. Feng Youlan said, while each specific discipline aims at the highest achievement in a particular field, Confucianism is concerned with the more fundamental purpose of the essential character of human beings, and this purpose is, in Confucianism's view, more fundamental than the other purposes. [5]

Confucianism is more concerned with the implementation of "Ren" than with the intellectual concept of "ren". As Wang Yangming said, "True knowledge is so called action, not action is not enough to be called knowledge." [6]Confucianism attaches importance to moral consciousness, and this moral consciousness must be put into practice through action, thus "listen to his words and observe his deeds" (Analects of Confucius - Gongye Chang), and to achieve "knowledge and action in unity is the key to becoming a "benevolent person". A disciple, Zi Lu, once asked Confucius about his life's ambition, and Confucius replied, "The old man is at ease, the friend is trustworthy, and the young man is in his arms" (Analects of Confucius - Gongye Chang). "Ren" is realized in the practice of social interpersonal relationship, without social practice, the purpose of life cannot be achieved.

In today's society, pragmatism and vulgar materialism are prevalent, and Confucianism, based on the purpose of "to be a benevolent man", emphasizes inner cultivation, which can guide the youth group to pay more attention to the inner spiritual world and build a strong spiritual dam. Although Confucianism sets "Ren" as a subjective mental activity as the purpose of life, it also sees the socio-historical factors in the process of realizing "Ren". The emphasis is not only on inner moral consciousness, but also on outer moral practice, emphasizing the "unity of knowledge and action". This positive attitude towards moral practice can be a good complement to the disadvantages of today's young people who emphasize theory over practice in the field of ethics.

\subsection{The ideal of life as a "gentleman"}

"To be a benevolent man" as the ultimate pursuit of life, and the corresponding ideal of life in reality is the achievement of "gentlemanly personality". Unlike the West's pursuit of a transcendent ideal of life, Confucianism's pursuit of the ideal of life rests entirely in the reality of life. On the one hand, Confucius opposed the idea of a sage who would leave reality behind to talk about "natural talent", and on the other hand, who opposed the idea of talking about human nature only in terms of material things, thus falling into the mundane. The gentleman is neither a divine nature that transcends humanity nor a bestial nature that extinguishes humanity, but a glorious image that originates from human nature and is revealed by the constant amplification of humanity.

If there are ideals in life, there are also ideals in society. Regarding the social ideal of Confucianism, there is a famous description in the chapter "The Book of Rites - Rites of Fortune": "The Way of the Great Way is also the world is public. We should select the best and the most capable, talk about faith and cultivate harmony, so that people are not alone in their relatives, not alone in their sons, so that the old will have an end, the strong will have a use, the young will have a growth, the widowed, the widowed, the lonely and the disabled will have a support, the men will have a share, the women will have a return. Goods are not necessary to be hidden from oneself, even if they are abandoned to the ground; forces are not necessary for oneself, even if they do not come from the body. It is a great commonwealth, that the schemes are closed and not raised, and the theft and disorder and thieves are not committed, so that the outer households are not closed." [7]Confucianism 
resorted to the ritual and music culture of the legendary Three Dynasties period for the realization of the above social ideals. " "Harmony is the essential part of ritual applications" (Xue Er, Analects of Confucius). The starting point of ritual and music culture is the "love" of kinship connected by blood ties, and the end is the ethical ties formed by this "love". The social ideal of Confucianism is the construction of a sound set of social and ethical principles, and love is the bridge and key to bridging the ideals of life and society.

On the relationship between personal and social ideals, Confucianism opposes the separation or opposition of personal and social ideals. Zhu Xi's commentary on "Wen, Liang, Gong, Jian, Rang" says: "The person whose virtues are so bright that he receives people"[8], which shows that the realization of the personality of the "gentleman" is in the midst of social relations. A gentleman is only possible in a society where differences exist, where individuals have the filial piety of father and son, the love of brother, the righteousness of ruler and subject, and the trust of friend because of their social status, and a gentleman is the synthesis of these human relationships. If there is only singularity or sameness, one cannot be a gentleman. The realization of the personality of the "gentleman" is necessarily formed under diverse social conditions, and thus the Confucian ideal of great government is linked to the ideal of the individual. The realization of the social ideal lies in the proper implementation of human love, and the realization of the individual ideal is empty if it is divorced from the social ideal.

The Confucian theory of the ideal of life is based on one's own personal experience, and the "gentleman's personality" that emerges from the ordinary life of each individual helps the growth of the youth community. The linking of personal and social ideals and the emphasis on the family resemblance of the personal and social ideals provide a reasonable path for the integration of the individual into society and contribute to the success of the youth population. Unlike theoretical teachings from the outside, the Confucian ideal of the "gentleman" in life provides a close inner motivation for every ordinary person to establish and realize his ideals in life.

\subsection{A "positive attitude to the world"}

The ideal of "benevolence" as the purpose of life and the pursuit of "gentlemanly" character in life determines the active and aggressive attitude of Confucianism. On why he was active in the world, Zeng Can once explained, "A scholar cannot help but be a man of great perseverance; the task is heavy and the road is long. Isn't it also important for benevolence to take care of itself?" (Analects of Confucius - Tabor) Zi lu had also explained, "There is no righteousness in not serving. The righteousness of the ruler and the minister can not to be abolished. The desire to pure and lofty but destroy the social rule. The gentleman's service is also to perform his righteousness, and the fail is already known." (Analects of Confucius - Weizi) The disciples' explanation can well reflect Confucius' thought that the reason why a gentleman actively enters the world lies, on the one hand, in the fact that a gentleman has a strong sense of moral mission. In traditional society, the scholars and scholars held themselves to be in control of the so-called "Orthodoxy" and were the spokesmen of the Heaven and the social order, alongside the imperial represented by the feudal kings. It becomes the basic mission of the intellectual community to ensure that the Tao of the previous kings are passed on from generation to generation. On the other hand, the moral responsibility of the gentleman lies in the fact that the gentleman has the power of intellectual discourse, and accordingly, he is also obliged to "edification of the masses". "If a gentleman learns Tao, so he should loves people" (Analects of Confucius - Yanghuo), and in order to achieve the ideal social form, a gentleman needs to spread this "benevolent love", to promote this "benevolent love" requires an active attitude of initiation into the world. 
Confucianism affirms the propriety of the gentleman's entry into the world in a virtuous society, but does not oppose the propriety of his exit from the world in the face of a nonvirtuous society. In the face of the alienated world of rites and music, we can still retreat to our original heart and preserve the heart of benevolence from the source, so that we can "seek benevolence and obtain it" (Analects of Confucius - Shu Zi). This human attitude of waiting for the right time not only gives individuals a more flexible approach to their interrelationships with society, but also brings us a confident and optimistic approach to life. This flexible Confucian approach to life, which is both out of and into the world, is of great significance to young people who are just entering the complexities of social life. On the one hand, we should be optimistic and enterprising like the young Marx, but on the other hand, we should be flexible in the face of difficulties and setbacks, and maintain the high moral subjectivity of "born with virtue in giving".

\subsection{The value of "righteousness over profit" in life}

Confucianism first of all affirms the legitimacy of individual material interests, and Confucius encourages people to pursue their legitimate personal interests in an ideal society, where it is not only reasonable but also desirable for anyone to obtain legitimate interests through his or her own efforts. In order for ordinary people to have high moral sentiments and "gentlemanly" personality, they must go through a process of "knowing the etiquette after the granary is enough", and the satisfaction of legitimate interests is the material basis of moral civilization. However, when interests go beyond the scope of the individual and form relations of interest between people, there may be conflicts of interest and confrontation of values, and "righteousness" is needed to reconcile these relations. "Righteousness is also appropriate", "righteousness" is the maintenance of the rational principle of the distribution of material interests in society, and is the essence of social norms. Confucianism outlines two general principles for dealing with the interests of people: first, "Do unto others as you would have them do unto you", and second, "Do unto others as you would have them do unto you, and do unto them as you would have them do unto you". The former ensures that the interests of others are not harmed, while the latter takes into account the interests of others while realizing its own. These two together constitute the general principle of Confucian "righteousness": to benefit others and oneself as much as possible without harming others, that is, to "consider others in one's own place" as Confucius said.

In the Confucian view, righteousness and profit do not normally constitute a contradictory relationship; "righteousness is the harmony of profit"; righteousness is an effective means of regulating conflicts of interest between society and individuals; a society with moral righteousness is often a win-win situation for both individual and collective interests. "By making more people happy in their lives through their own struggle, which is on a social level, they realize their own value in life. And then make your own efforts for the nation, for the country, for humanity, for all beings, and at a higher level, realize the value of your life." [9] When righteousness fails in social life, it may result in the misallocation of benefits or even conflict. "It is a shame for a state to be rich and noble when there is no righteousness" (Analects of Confucius - Taibe), and profit obtained in violation of righteousness is undesirable, because a dysfunctional society cannot lead to the realization of our own values, and its gain must be unjustified, and unjustified profit is not only unhelpful to the realization of individual values, but also harmful to the realization of social values. Under special circumstances, when personal interests and social interests are in conflict and cannot be reconciled, the principle is to put righteousness before profit, and when necessary, even to sacrifice personal interests for the sake of the collective interests and to maintain social order, so as to "sacrifice life for righteousness". 
The Confucian theory of the value of life affirms, on the one hand, the reality of human material interests and the legitimacy of the individual's pursuit of reasonable material interests. On the other hand, righteousness is used to balance individual and collective interests and to achieve the unity of individual and social values. Confucianism places the realization of individual values in the realization of social values and uses the realization of social values as the basis for the realization of individual values. In addition to realistic material interests, a higher moral requirement was placed on the gentleman: for thousands of years, "righteousness over profit" and "sacrificing one's life for righteousness" have become the consistent pursuit of intellectuals in the face of family and national affairs. This collective and big picture consciousness has a good corrective effect on the extreme individualism prevalent today and still deserves to be learned by the youth in general.

It can be seen from the above description that Confucianism has designed the ideal of "gentlemanly personality" based on the purpose of "benevolence" in life, and has always maintained a positive and optimistic, yet flexible, attitude towards life in order to achieve the unity of personal and social interests. The many Confucian discourses on the problems of life can serve as a useful supplement to education on the Marxist outlook on life, so that students' understanding of the outlook on life is not abstract and difficult to understand, and their understanding of the Marxist outlook on life is not far-fetched and evanescent, and is still extremely enlightening for the establishment of the outlook on life of young people today.

Fundamental Project: Shaanxi Provincial Research on Major Theoretical and Practical Issues in Thought and Politics, "Research on the Path of Integrating Excellent Chinese Traditional Culture into the Teaching of Civics Classes in Colleges and Universities" (Project No.: Sz20119)

\section{Reference}

1. Selected Important Documents since the 18th National Congress (part I), Central Literature Publishing House, pp.277, Beijing(2014)

2. Y. F. Li, "Analysis of the Survey on the Basic Situation of College Students' Outlook on Life in 2019," Thought Education Research, 11(2020)

3. Z. H. Zou, "The Good Life : 'The ensemble of traditional Confucian ethical thought on happiness and Marxist concept of happiness', Journal of Theory,(2021)

4. J. P. Xi, "Xi Jinping's speech at the opening session of the international symposium commemorating the 2565th anniversary of Confucius' birth and the fifth general assembly of the International Confucian Federation," People's Daily, pp.02, (2014)

5. Y. L. Feng, A Brief History of Chinese Philosophy, Peking University Press, (2013)

6. Y. M. Wang, The Complete Works of Wang Yangming (New Edition), Zhejiang Ancient Books Publishing House, pp.646, Hangzhou(2010)

7. W. J. Wang, A Translation and Interpretation of the Book of Rites (part I), China Book Bureau, pp.287,Beijing(2001)

8. X. Zhu (Song), Collected Notes on the Four Books and Chapters, China Book Bureau, pp.53, Beijing(2011)

9. Y. Ren, X. R. Su, "The Confucian view of life and the development of traditional cultural resources in ideological and political education", Higher Education Forum, No. 8, (2019) 